\title{
Dryas as a Model for Studying the Root Symbioses of the Rosaceae
}

\author{
Benjamin Billault-Penneteau', Aline Sandré1, Jessica Folgmann' ${ }^{1}$, Martin Parniske ${ }^{1 \star}$ and \\ Katharina Pawlowski ${ }^{*}$
}

1 Institute of Genetics, Faculty of Biology, LMU Munich, Martinsried, Germany, ${ }^{2}$ Department of Ecology, Environment and Plant Sciences, Stockholm University, Stockholm, Sweden

\section{OPEN ACCESS}

Edited by:

Stefan de Folter,

Centro de Investigación y de Estudios Avanzados (CINVESTAV), Mexico

Reviewed by:

Pernille Bronken Eidesen, The University Centre in Svalbard,

Norway

Pascal Ratet,

UMR9213 Institut des Sciences des

Plantes de Paris Saclay (IPS2), France

*Correspondence:

Martin Parniske

parniske@/mu.de

orcid.org/0000-0001-8561-747X

Katharina Pawlowski

katharina.pawlowski@su.se

orcid.org/0000-0003-2693-885X

Specialty section:

This article was submitted to Plant Development and EvoDevo, a section of the journal

Frontiers in Plant Science

Received: 21 November 2018

Accepted: 02 May 2019

Published: 04 June 2019

Citation:

Billault-Penneteau B, Sandré A,

Folgmann J, Parniske $M$ and

Pawlowski K (2019) Dryas as a Model

for Studying the Root Symbioses

of the Rosaceae.

Front. Plant Sci. 10:661.

doi: 10.3389/fp/s.2019.00661
The nitrogen-fixing root nodule symbiosis is restricted to four plant orders: Fabales (legumes), Fagales, Cucurbitales and Rosales (Elaeagnaceae, Rhamnaceae, and Rosaceae). Interestingly all of the Rosaceae genera confirmed to contain nodulating species (i.e., Cercocarpus, Chamaebatia, Dryas, and Purshia) belong to a single subfamily, the Dryadoideae. The Dryas genus is particularly interesting from an evolutionary perspective because it contains closely related nodulating (Dryas drummondii) and non-nodulating species (Dryas octopetala). The close phylogenetic relationship between these two species makes Dryas an ideal model genus to study the genetic basis of nodulation by whole genome comparison and classical genetics. Therefore, we established methods for plant cultivation, transformation and DNA extraction for these species. We optimized seed surface sterilization and germination methods and tested growth protocols ranging from pots and Petri dishes to a hydroponic system. Transgenic hairy roots were obtained by adapting Agrobacterium rhizogenes-based transformation protocols for Dryas species. We compared several DNA extraction protocols for their suitability for subsequent molecular biological analysis. Using CTAB extraction, reproducible PCRs could be performed, but $\mathrm{CsCl}$ gradient purification was essential to obtain DNA in sufficient purity for high quality de novo genome sequencing of both Dryas species. Altogether, we established a basic toolkit for the culture, transient transformation and genetic analysis of Dryas sp.

\section{Keywords: Dryas, model-plant, Dryas drummondii, Dryas octopetala, Rosaceae, genome comparison}

\section{INTRODUCTION}

Nitrogen and phosphate are key nutrients for plant growth, but their availability is limited, especially in alkaline and calcareous soils (Vitousek et al., 2010; Lambers et al., 2012). Plants, with their limited capacity to retrieve nutrients from the soil, profit from interactions with beneficial microorganisms. Root endosymbiosis with arbuscular mycorrhizal fungi or nitrogen fixing bacteria are examples of this kind of interaction, where the microsymbiont is accommodated within root cells, leading to a gain of function that enables the plant to survive or even thrive in previous uninhabitable environments. Among terrestrial plants, the vast majority $(80 \%)$ is able to develop arbuscular mycorrhiza (AM), a symbiosis with fungi of the Glomeromycotan (Delaux et al., 2013); one of the main benefits of the AM symbiosis is the ability of the fungi to improve the host plants' access to phosphate. Despite the advantages of this symbiosis, some plant lineages have lost genes essential for its establishment. One such lineage is the Brassicaceae family that comprises the 
model plant Arabidopsis thaliana (Cosme et al., 2018). Another symbiotic system evolved for the acquisition of nitrogen through the cooperation with nitrogen fixing Frankia or rhizobia bacteria, the nitrogen-fixing root nodule symbiosis (RNS). The symbiosis is named after the specialized root organs formed by the plant, root nodules, which provide physiological conditions for the bacteria to fix atmospheric nitrogen and export a product of nitrogen fixation to the host plant. This endosymbiosis is restricted to plant species in the related orders Fabales, Fagales, Cucurbitales and Rosales, forming the FaFaCuRo clade (Soltis et al., 1995; Werner et al., 2014; Griesmann et al., 2018). Legumes (Fabales) and Parasponia sp. (Cannabaceae, Rosales) interact with rhizobia, while all other RNS forming plant species interact with the actinobacterium Frankia and consequently are called actinorhizal plants.

Genetic dissection of rhizobial symbiosis, mainly two model legumes - Medicago truncatula (Barrel medic) and Lotus corniculatus L. (bird's-foot trefoil) var. japonicus, - has revealed symbiosis-related genes that are essential for nodule organogenesis, bacterial infection, and nitrogen fixation (see, e.g., Geurts et al., 2016). Recent phylogenomic studies have revealed that although most current members of the FaFaCuRo clade cannot form root nodules, the common ancestor of the FaFaCuRo clade was able to enter a symbiosis (Griesmann et al., 2018; van Velzen et al., 2018). However, it is not clear whether this ancestral symbiosis involved the formation of root nodules (Parniske, 2018). Due to their common origin, several similarities exist between actinorhizal and rhizobial symbioses, and the transfer of knowledge from legumes to actinorhizal plants improves our understanding of the main processes underlying the symbiosis with Frankia bacteria. Nevertheless, important aspects of actinorhizal symbioses remain unknown (Pawlowski and Bisseling, 1996; Perrine-Walker et al., 2011; Van Nguyen and Pawlowski, 2017). Consequently, research on actinorhizal plants could allow us to better understand the evolution of divergent symbiotic processes in RNS.

The Rosaceae family, belonging to the order Rosales, is globally the 4th most important plant family in terms of economic value (Vallée et al., 2016). Surprisingly, from ca. hundred Rosaceae genera only four, forming the basal subfamily Dryadoideae (Xiang et al., 2016), have been described to contain actinorhizal species that are able to enter a nitrogen-fixing RNS with Frankia bacteria (Pawlowski and Demchenko, 2012). The most basal genus of the Rosaceae, Dryas, is one of the most dominant dwarf shrubs among the arctic plant genera in terms of biomass. The taxonomy within the Dryas genus is controversial due to the existence of hybrids that occur naturally in the wild (Packer, 1994; Philipp and Siegismund, 2003). In areas where different Dryas species cohabit, natural hybrids were described between Dryas integrifolia and Dryas octopetala (Philipp and Siegismund, 2003), or between Dryas. drummondii and D. integrifolia (known as D. $x$ wyssiana). The German botanist Franz Sündermann also created $D$. $x$ suendermannii by crossing D. drummondii with D. octopetala (Packer, 1994), as part of the collection of the "Botantischen Alpengarten Sündermann" at Lindau, Germany, where the hybrids are maintained by clonal propagation.
Currently, three Dryas species, D. drummondii, D. integrifolia, and $D$. octopetala, are recognized; however, the genus is in need of taxonomic revision (Porslid, 1947; Böcher et al., 1968; Hultén, 1968; Yurtsev, 1997; Philipp and Siegismund, 2003; Skrede et al., 2006). The genus Dryas is unique in that it contains closely related nodulating and non-nodulating species which makes it an ideal model to study the evolution of root symbioses. Nodulation was reported for the first time in 1967 (Lawrence et al., 1967) in the North American species D. drummondii (Newcomb, 1981; Kohls et al., 1994; Figure 3A). The other species appear to be non-nodulating (Becking, 1970; Markham, 2009), but all Dryas species form ectomycorrhiza (Melville et al., 1988; Ryberg et al., 2009; Bjorbækmo et al., 2010; Botnen et al., 2014). The only exception may be D. drummondii because it has been described as ectomycorrhizal only on one occasion (Fitter and Parsons, 1987). The question whether this species can form ectomycorrhiza requires further examination.

The arctic-alpine species $D$. octopetala has a particularly wide distribution; it can be used for mapping refugial isolation and postglacial expansion during the glaciation in the Pleistocene in northern Europe (Philipp and Siegismund, 2003; Skrede et al., 2006). The plants typically grow in alkaline calcareous soils (Crocker and Major, 1955) and thus face nutritional limitations especially in terms of nitrogen and phosphorus (Lambers et al., 2012). The presence and abundance of Dryas species across all arctic and alpine tundra's makes this genus a key player in arctic phylo- and bio-geography (Tremblay and Schoen, 1999; Skrede et al., 2006), landscape ecology (Eichel et al., 2016; Eichel et al., 2017) and mycology community ecology (Väre et al., 1992; Ryberg et al., 2009; Bjorbækmo et al., 2010; Brunner et al., 2017). The genus is of particular importance in research on climate change (see, e.g., McGraw et al., 2014; Gillespie et al., 2016; Panchen and Gorelick, 2017). Therefore, Dryas species also are integral to Citizen Science Projects, e.g., the Spatial Food Web Ecology Group of the University of Helsinki use Dryas sp. as base of two Ecosystem Ecology projects, the Arctic Parasitoid Project and the Global Dryas Project ${ }^{1}$, and the Climate Impact Research Centre in Abisko also includes Dryas octopetala in their target plants ${ }^{2}$.

Dryas species are diploid with an estimated haploid genome size of $250 \mathrm{Mbp}$ (Griesmann et al., 2018) distributed over nine chromosomes (Potter et al., 2007), less than Malus $\times$ domestica (apple) which is diploid or triploid with $750 \mathrm{Mbp}$, or Rosa which is tetraploid or triploid with $600 \mathrm{Mbp}$ (Jung et al., 2013). The genome sequence of $D$. drummondii obtained from DNA purified with the protocol described here is publicly available; all data have been deposited in GigaDB (Griesmann et al., 2018). This small genome, combined with a generation time of less than a year, makes Dryas suitable as model genus for the Rosaceae family.

In this study, we focused on D. drummondii and D. octopetala. We omitted $D$. integrifolia because of its high similarity with D. octopetala (Skrede et al., 2006), the latter being more accessible and better researched. The close relation between $D$. drummondii and D. octopetala allows genomic comparisons in order to

\footnotetext{
${ }^{1}$ https://www.helsinki.fi/en/researchgroups/spatial-food-web-ecology/research ${ }^{2}$ https://www.arcticcirc.net/our-projects/
} 
identify genes specifically involved in plant root endosymbiosis. We present the advances achieved in the development and adaptation of protocols in order to use Dryas as a model genus in Rosaceae research as well as to study the evolution of root symbioses.

\section{MATERIALS AND METHODS}

\section{Dryas Seeds and Ecotypes}

Seeds of D. drummondii DA462 and D. octopetala DA460 were purchased from the seed producer Jelitto (Schwarmstedt, Germany). The Nymphenburg Botanical Garden of Munich supplied seeds for D. drummondii BGM. Ecotypes Albe. (origin Clearwater County, Alberta, Canada, collected in 2000); and Alas. (origin Alaska, United States, collected in 2002) were found in and supplied by the KEW Millennium Seed Bank (Royal Botanic Gardens, Kew, London, United Kingdom). D. octopetala ecotype E548 was harvested in the Italian Alps (approximate GPS coordinates: $46^{\circ} 24^{\prime} 36.7^{\prime \prime} \mathrm{N} 11^{\circ} 37^{\prime} 48.2^{\prime \prime} \mathrm{E}$ ) by Anna Heuberger.

\section{Primers}

Primers were designed based on the first draft genome of D. drummondii (Griesmann et al., 2018). They are as follows: GADPH forward 5'-CCCCAGTACGAATGCTCCCATGTTT G-3', GADPH reverse 5'-TTAGCCAAAGGAGCAAGACAGTT GGTGG-3'; EF1-a forward 5'-TGGGTTTGAGGGTGACAACA TGA-3'; EF1-a reverse 5'-GTACACATCCTGAAGTGGGAGAC GGAGG-3'; 26S rRNA forward 5'-TACTGCAGGTCGGCAAT CGG-3', 26 S rRNA reverse 5' -TCATCGCGCTTGGTTGAAAA$3^{\prime}$. ITS primers were designed based on Cheng et al. (2016): ITS forward 5'-CCTTATCAYTTAGAGGAAGGAG-3', ITS reverse 5'-RGTTTCTTTTCCTCCGCTTA-3'.

\section{Seed Storage and Sterilization}

Based on advice from seed producers and on results from Nichols (1934) who observed that without prior refrigeration, germination of several alpine species was considerably reduced, we assumed that seeds of Dryas species might require cold stratification prior to germination and therefore stored them at $4^{\circ} \mathrm{C}$. Dryas seeds were surface sterilized by immersion in $30 \%$ $\mathrm{H}_{2} \mathrm{O}_{2}$ (10 min for D. octopetala; $15 \mathrm{~min}$ for D. drummondii) and washed three times with sterile $\mathrm{H}_{2} \mathrm{O}$. These experiments were performed with four biological replicates per species, with at least 100 seeds per replicate.

\section{Growth Systems}

Sterilized seeds were transferred on $1 \%$ agar-water plates and incubated in the dark at $22^{\circ} \mathrm{C}$ for 12 and 8 days for D. octopetala and $D$. drummondii, respectively. Several sources of agar were tested such as Bacto ${ }^{\mathrm{TM}}$ agar (Becton Dickinson and company) and agar Kalys HP 696 (Kalys SA, Bernin, France). The germination assays were set up in the dark because this reportedly increased germination rates Bliss (1958). After germination, seedlings of Dryas spp. were grown on plates, in a hydroponic system or in pots.
Growth on plates was performed on $1 / 4$ Hoagland's $\mathrm{pH} 5.8$ (using the protocol for $\mathrm{N}$-free medium; Hoagland and Arnon, 1950 ) and adding $1 \mathrm{KNO}_{3}$ to a final concentration of $1 \mathrm{mM}$ ) with $0.4 \%$ of Gelrite (Duchefa, Haarlem, Netherlands), at $22^{\circ} \mathrm{C}, 55 \%$ of humidity with $16 \mathrm{~h}$-light/ $8 \mathrm{~h}$-dark cycles. After 1 week, plantlets were transferred either into pots or Weck jars (containing production substrate A210; Stender AG, Germany) or into a hydroponic system.

The hydroponic system consisted of a standard $1 \mathrm{~mL}$ pipette tip box in two parts: the bottom part contained $250 \mathrm{~mL}$ of growth medium ( $1 / 4$ Hoagland, $\left.1 \mathrm{mM} \mathrm{KNO}_{3}, \mathrm{pH} 5.8\right)$ and the tip holder with 24 holes in which the plantlets were inserted (Figure 2). To avoid seedlings or young plantlets falling into the medium compartment, the holes were covered with adhesive tape and plantlets were introduced through thin slits cut into the tape. The growth medium was changed twice per week. The hydroponic system was kept in a growth cabinet at $22^{\circ} \mathrm{C}, 55 \%$ humidity with $16 \mathrm{~h}$-light/ $8 \mathrm{~h}$-dark cycles for a maximum of 4 months.

Plants in pots were transferred to the greenhouse (day temperature $21-24^{\circ} \mathrm{C}$, night temperature $18-21^{\circ} \mathrm{C}$, with additional lighting from $6: 00$ to $10: 00 \mathrm{~h}$ and from 15:00 to 22:00 h). The pots were filled either with sand:vermiculite (2:1) or with propagating substrate (A210 Stender AG, Germany). Note that temperature and light conditions were applied as available in our plant growth facilities and not experimentally optimized for Dryas.

\section{Cutting Propagation}

For clonal propagation, young and soft shoots of Dryas spp. were cut after the third internode $(2-5 \mathrm{~cm})$ above the woody part of the shoot. These explants were directly transferred into moist production substrate A210 (Stender AG, Germany), then kept under plastic cover in the greenhouse. High humidity was maintained under the cover by spraying with water every 2 days for 2 weeks; thereafter, spraying was stopped and cuttings were kept in moist soil under the cover until new leaves had developed and the covers were removed. Three series of ca. 20 cuttings per species were cultivated in the greenhouse during different seasons.

\section{Hairy Root Transformation}

We established a protocol for hairy root transformation in Dryas spp. by adapting Lotus protocols. The Agrobacterium rhizogenes strain AR1193 (Stougaard et al., 1987) was used because it had been shown to be very efficient for some plant species such as pea (Clemow et al., 2011) and because it was one of the strains available in our lab previously successfully tested for Lotus japonicus hairy root transformation.

Agrobacterium rhizogenes AR1193 bacteria carrying a Golden Gate LIII $\beta$ F A-B (Binder et al., 2014) plasmid containing the mCherry gene under control of the Ubiquitin promoter (AtUbi10pro) as transformation marker (Pimprikar et al., 2016), were grown in liquid culture (LB medium with $50 \mu \mathrm{g} \mathrm{mL}-1$ each of rifampicin, carbenicillin and kanamycin) at $28^{\circ} \mathrm{C}$ overnight. Bacteria were collected via a centrifugation step $(15 \mathrm{~min}$ at $4.369 \times g)$ and resuspended in water to obtain the wanted $\mathrm{OD}_{600}(0.01 ; 0.1 ; 1 ; 7.2)$. Cut hypocotyls of 
10-12 days old axenically grown Dryas spp. seedlings were dipped in the bacteria suspension and placed on $1 / 4$ Hoagland (1 $\mathrm{mM} \mathrm{KNO}_{3}, \mathrm{pH}$ 5.8), 0.4\% Gelrite (Duchefa, Haarlem, The Netherlands) plates. The plates were kept for 4 days in the dark at $22^{\circ} \mathrm{C}$, then under a $16 \mathrm{~h}$-light $/ 8 \mathrm{~h}$-dark cycle with 55\% humidity. To prevent overgrowth of bacteria and dehydration, the plants were transferred onto new plates every week. Four to six weeks after transformation, roots were screened using a Leica MZ16 FA stereomicroscope (Leica Microsystems GmbH, Wetzlar, Germany) using the N3 filter from Leica (BP 546/12;600/40).

\section{DNA Extraction and PCR Reactions}

The $\mathrm{CsCl}$ gradient DNA extraction method was performed according to Ribeiro et al. (1995). Six to ten grams of leaves (mix of young and old from the same plant) were ground by hand using pistil and mortar with $4 \mathrm{~g}$ of PolyclarAT in liquid nitrogen. For the other extraction methods, the two youngest leaves of a shoot with the apical meristem were used as starting material. After being shock frozen in liquid nitrogen, they were ground with a Retsch Mill MM400 (Fa. Retsch, Haan, Germany) two times at $30 \mathrm{~Hz}$ for $30 \mathrm{~s}$ in $2 \mathrm{~mL}$ Eppendorf tubes containing $2 \mathrm{~mm}$ diameter stainless steel beads each. The "classical CTAB" extraction method is described in Doyle and Doyle (1987), whereas the "PVP/NaCl" extraction method was developed by Khanuja et al. (1999) based on the classical CTAB method.

PCRs were performed on $1 \mu \mathrm{l}$ of DNA (20-700 ng of DNA, usually ca. $100 \mathrm{ng}$ ) using GoTaq ${ }^{\circledR}$ DNA polymerase (Promega, Germany), SYBR Green buffer and $0.2 \mu \mathrm{M}$ of each primer. Amplifications were carried for $5 \mathrm{~min}$ at $95^{\circ} \mathrm{C}$, followed by 35 cycles $\left(30 \mathrm{~s}\right.$ at $95^{\circ} \mathrm{C}, 30 \mathrm{~s}$ at $60^{\circ} \mathrm{C}$, and $40 \mathrm{~s}$ at $\left.72^{\circ} \mathrm{C}\right)$, and a final extension for $1 \mathrm{~min}$ at $72^{\circ} \mathrm{C}$. Electrophoresis of a $4 \mu \mathrm{L}$ of PCR reaction was performed on a $3 \%$ agarose gel for $100 \mathrm{~min}$ at 130 V. DNA was visualized with UVP UV solo touch from Analytik Jena@ (Jena, Germany) after incubation of the gel for $10 \mathrm{~min}$ in an Ethidium bromide bath at $2 \mathrm{ng} \mathrm{\textrm {mL } ^ { - 1 }}$.

\section{RNA Extraction}

Leaves, seedlings and root systems were shock frozen in liquid nitrogen. RNA of ground material (with the same procedure previously described for DNA extraction) was extracted using the Spectrum ${ }^{\mathrm{TM}}$ Plant Total RNA Kit (Sigma-Aldrich, CA, United States) without adaptation in the protocol except for older and thicker leaves for extraction of which Polyclar AT was added. The RNA was treated with DNAse (Invitrogen ${ }^{\text {TM }}$ TURBO DNAfree Kit; Carlsbad, CA, United States) and tested for purity and integrity with a Bioanalyzer from Agilent (Agilent Technologies, Palo Alto, CA, United States). Twelve independently isolated RNA samples were analyzed.

\section{RESULTS AND DISCUSSION}

To establish Dryas as new model genus in the laboratory, we developed cultivation protocols under controlled conditions.

\section{Dryas Seeds and Germination}

Fungal contamination of seeds was often observed, whether they were collected in the field or obtained from a professional seed producer. In our study, white fungal hyphae growing out of the seeds led to seedling death at an early stage. Dryas seeds were quite sensitive to different surface sterilization procedures: any traces of ethanol would completely inhibit germination, while the thinness of the seed coat rendered the use of sulphuric acid for scarification risky. Furthermore, the contaminating fungi were quite resistant to $\mathrm{NaOCl}$. However, after stratification of Dryas seeds at $4^{\circ} \mathrm{C}$ (Figure 1A), most efficient sterilization and highest germination rates were observed using hydrogen peroxide. Indeed approximately $100 \%$ of D. octopetala seeds and between 99 and $100 \%$ of D. drummondii seeds were free of contaminants after the procedure. Four replicates, with at least 100 seeds per replicate, were observed every 2 days. For D. drummondii, the maximal germination rate $(85 \%)$ was obtained 8 days post-sterilization, whereas the maximum germination rate of $D$. octopetala, ca. $40 \%$, was only reached 12 days post-sterilization (Figure 1C).

The time difference of 4 days to reach maximum germination observed between D. drummondii and Dryas octopetala was consistently observed at least within the samples tested: seeds of all $D$. drummondii seed sources examined germinated within 8 days and $D$. octopetala seeds from all sources available within 12 days. This phenotype was consistent not only for seeds produced in the greenhouse or botanical garden during the same month, but also for commercial seeds, the age of which was unknown. However, given that $D$. octopetala has a very wide distribution, it is possible that the two seed sources examined do not encompass the entire variability of the species.

\section{Dryas Growth Systems}

We examined different growth conditions and systems including Gelrite and agar plates, hydroponic systems and classical pots. These distinct growth systems combine diverse advantages for research such as axenic culture, conditions for root system observations and for inoculation with the microsymbiont. Frankia strains able to nodulate $D$. drummondii have not yet been successfully cultured (Normand et al., 2017), necessitating infection with crushed nodules. As these nodules carry a rich fungal and bacterial microbiome on the surface, inoculation of Dryas with these nodules while maintaining a gnotobiotic system is challenging. On the other hand, plants grown in pots do not represent the most suitable system for root analyses. The process of cleaning the soil from the roots stresses the plant and furthermore, the harvesting of root systems entails the risk of breaking thin and fragile lateral roots and root hairs. To circumvent this drawback, plants can be grown in Petri dishes. For Dryas species this system was suited for early stages of development; for experiments exceeding 4-5 weeks, root and shoot growth required more space. Furthermore, shielding of plates never totally protected the roots from light, and a long exposure of roots to light tends to interfere with the analysis of root responses to any treatment. Exposure of roots to direct light modifies their transcriptome (Hemm et al., 2004) and often 


\section{D. drummondii}

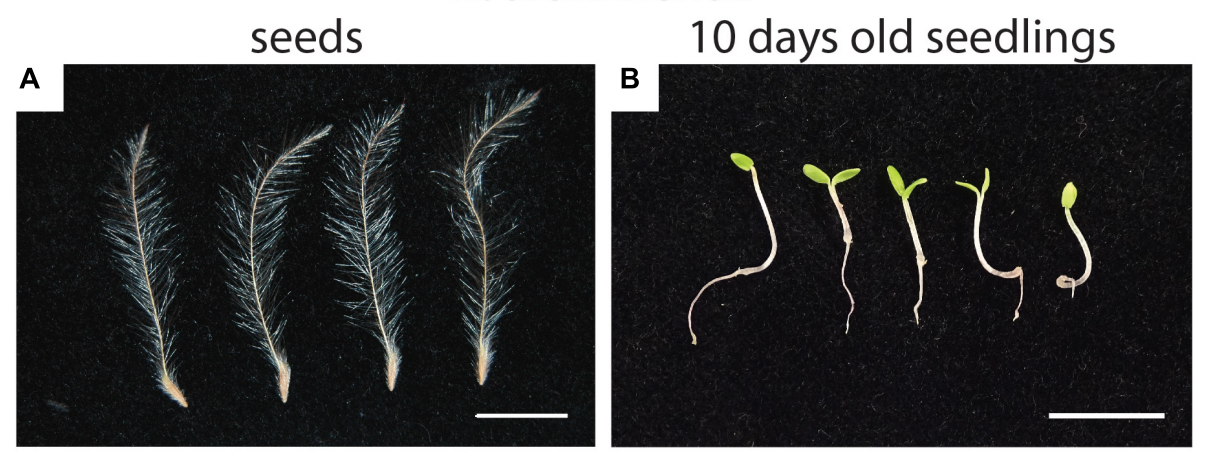

C

Dryas germination rate

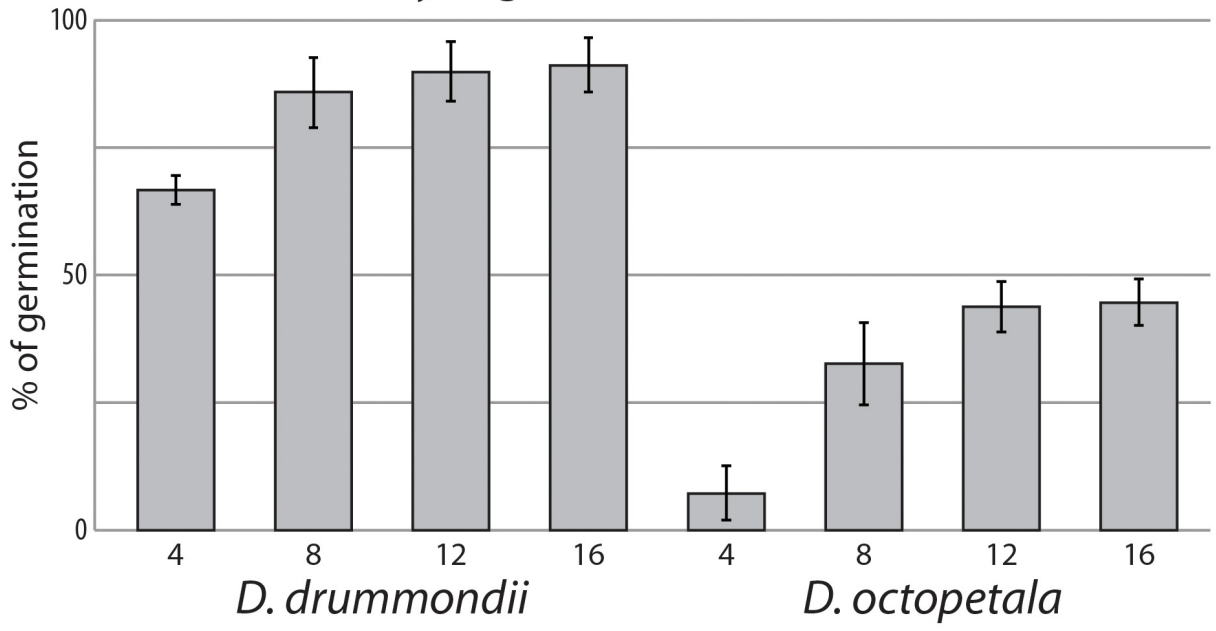

FIGURE 1 | Dryas spp. from seeds to seedlings. (A) Isolated anemochorous silky-feathery achenes from Dryas drummondii. (B) 10-day-old seedlings of D. drummondii. Scale bars denote $1 \mathrm{~cm}$. (C) Time course of Dryas sp. germination after seed surface sterilization. Displayed are means $(n=4$ biological replicates with at least 100 seeds per replicate) and standard errors.

leads to stress responses, which can perturb the analyses and cause misleading effects. Hydroponic systems offer the possibility to observe the roots in a non-invasive way while also shielding them from light. They can be used with or without an inert substrate that mimics physical soil contact. The fact that Dryas species can grow in well-aerated soil but can also tolerate flood periods (West et al., 1993), suggested the use of hydroponics as a method of choice.

Once germinated and grown on $1 \%$ agar plates with classical plant media like B5 or MS (Murashige and Skoog, 1962; Gamborg et al., 1968; Duchefa, Haarlem, Netherlands) or Fåhræus medium (Fåhraeus, 1957) with $1 \mathrm{mM} \mathrm{KNO}_{3}$, Dryas species seedlings turned reddish, likely due to $\mu$ lanin production, a response typically interpreted as stress- or defense-related. This anthocyanin production was less pronounced when the seedlings were grown on $0.4 \%$ Gelrite with $1 / 4$ strength Hoagland medium containing $1 \mathrm{mM} \mathrm{KNO}_{3}$ (Figure 1B). Moreover, after 2 weeks on plates, Dryas spp. plantlets grown on $1 / 4$ strength Hoagland medium showed darker green cotyledons and further developed root systems than on B5 medium. Thus, among the tested media for Dryas seedlings on gel-forming media, the best results were obtained with $0.4 \%$ Gelrite containing $1 / 4$ strength Hoagland solution.

After germination on plates, Dryas species. plantlets were transferred to a hydroponic system (Figure 2A) with $1 / 4$ Hoagland solution. In this system Dryas species plants grew and developed without obvious stress symptoms like accumulation of anthocyanins; they formed well-developed primary and lateral roots, and the speed of shoot development resembled that of pot-grown plants (Figure 2B). Altogether, Dryas species plants adapted very well to the hydroponic system tested. The absence of gel and soil substrates offers the opportunity to perform non-invasive observations of roots.

\section{Sexual Propagation of Dryas Species}

Dryas is a perennial plant genus. D. drummondii has been found to flower in its fifth year (Lawrence et al., 1967), indicating a long generation time that renders crossing experiments difficult. However, nodulation, plant growth and flowering processes in Dryas sp. seem to be extremely dependent on the 
A

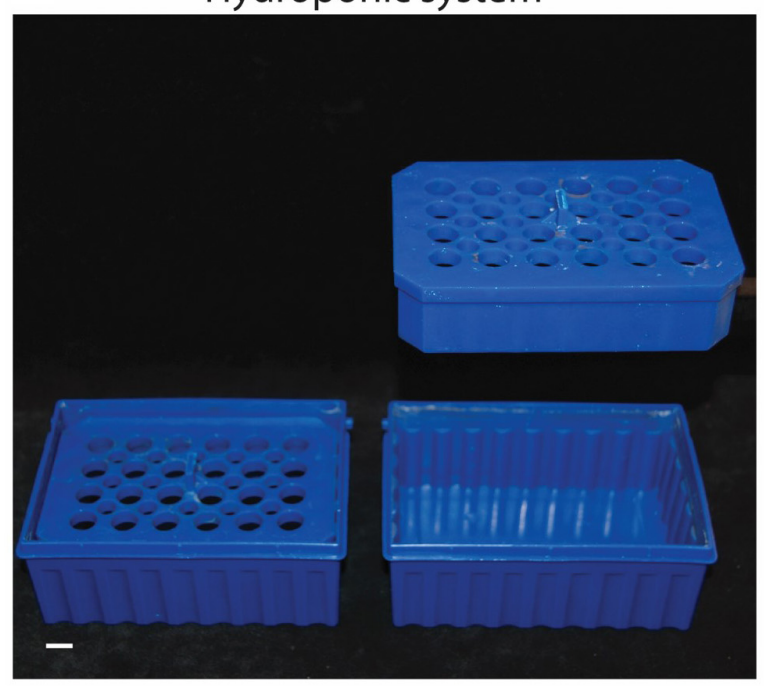

B D. drummondii in hydroponic system

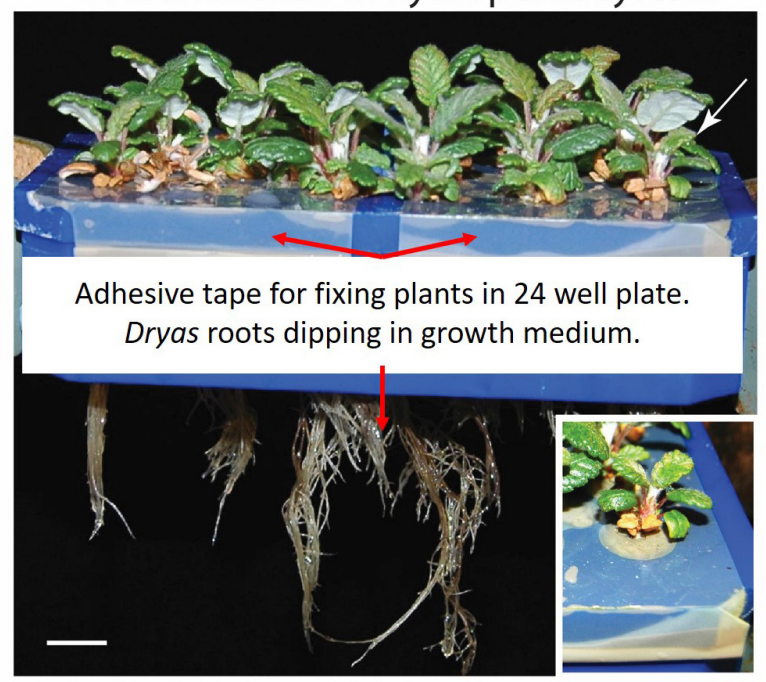

FIGURE 2 | Hydroponic system for Dryas spp. (A) Overview of the hydroponic system: assembled (left) and split up (right). (B) Hydroponic culture of Dryas drummondii after 7 weeks in the hydroponic system; the white rectangle shows a close-up view of the plant labeled with a white arrow. Scale bars denote $1 \mathrm{~cm}$.

environment and on light quality and intensity (Kohls et al., 1994). Therefore, we attempted to reduce the generation time under greenhouse conditions.

In our study, flower and seed production did not occur when plants were grown at a distance of $2 \mathrm{~m}$ from standard highpressure mercury vapor lamps (providing $90 \mu \mathrm{mol} \mathrm{m}{ }^{-2} \mathrm{~s}^{-1}$ at the plant level) used in initial trials (fluorescent lamps were not tried for flowering as seedlings from both species were growing significantly more slowly under them than under mercury vapor lamps for the first 5 weeks after germination). However, when the plants were placed at a distance of $2 \mathrm{~m}$ under high-pressure sodium vapor lamps $\left(150 \mu \mathrm{mol} \mathrm{m} \mathrm{m}^{-2} \mathrm{~s}^{-1}\right)$ for $16 \mathrm{~h}$ per day, flowering was induced (Figures 3B-D). High-pressure sodium lamps provide light with a richer emission in yellow-orange and a red/far red ratio shifted to the far red compared to standard high-pressure mercury vapor lamps and fluorescent lamps. The flowers produced seeds (Figure 1A) within less than a year after germination, whether the plants originated from cuttings or from sexual propagation. This is a far shorter generation time than the 5 years required for $D$. drummondii according to Lawrence et al. (1967). In the field, Dryas spp. flower primordia are formed during the summer, i.e., far in advance of flowering, which occurs in the next year shortly after snowmelt, with most individuals flowering within a month (Lawrence et al., 1967). This behavior suggests that the development of floral primordia and blooming depends on photoperiod or vernalization (or both). It is surprising that light from high-pressure sodium lamps, characterized by a lower red/far red ratio, leads to induction of flowering in an arctic/alpine species like D. octopetala, and of a species that has been described as extremely shade-sensitive (D. drummondii; Cooper, 1931). We observed that plants grew much better outdoors than in the glasshouse, but did not identify the limiting parameters. At any rate, changes of light period and temperature might further speed up the induction of flowering and shorten the generation time.

Seed set under greenhouse conditions occurred at ca. $75 \%$ of all D. drummondii flowers and at ca. $65 \%$ of all D. octopetala flowers. In their natural habitat, Dryas species combine autogamy and allogamy; seed set is improved when insects are available for pollination (Kevan, 1975; Roslin et al., 2013; Tiusanen et al., 2016, 2019). In the greenhouse, while some insects were usually present, seeds would be formed by flowers covered with paper bags, indicating that all seed batches used gave rise to plants that could perform self-fertilization.

Manual pollination was performed in the greenhouse and in a botanical garden to obtain hybrids. While the large and open flowers of D. octopetala (Figure 3D) made manual pollination possible, D. drummondii flowers were never completely open during full bloom (Figure 3C). Therefore, crossings of female D. octopetala with male D. drummondii were attempted. However, these attempts were not successful. Flowers of species contain multiple stamens, and often, after manual pollination it turned out that not all of them had been removed.

Altogether, sexual reproduction of Dryas spp. was feasible in a laboratory context when sufficient light intensity of a suitable spectrum was provided.

\section{Clonal Propagation of Dryas spp.}

Given that Dryas spp. are partially allogamous and experimental studies require homogenous plant material, the use of Dryas as a model genus requires an easy protocol for vegetative propagation. In the wild, clonal growth of Dryas species enables individuals to persist and grow in extreme environments where sexual proliferation is often unsuccessful (Wookey et al., 1995), and where individual clones of $D$. octopetala commonly live for more than 100 years (Kihlman, 1890; Crawford, 1989). Thus, clonal 

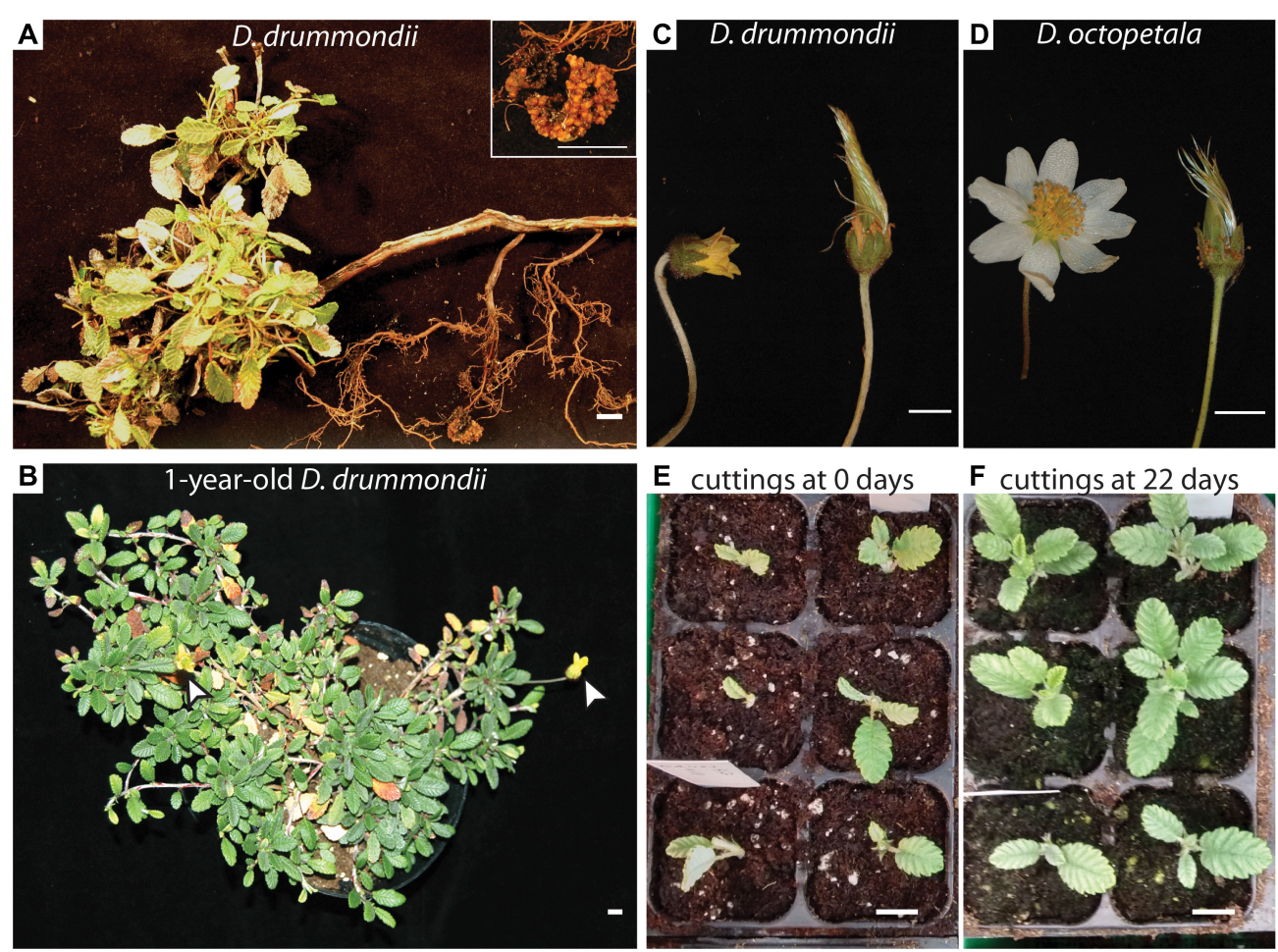

FIGURE 3 | Sexual and vegetative propagation of Dryas spp. (A) Part of a Dryas drummondii plant with a dense leaf rosette and lignified roots, coming from a woody shoot, bearing a nodule (shown magnified in the inset). The plant was collected in the Nymphenburg Botanical Garden of Munich. (B) 1-year-old D. drummondii plant flowering in the greenhouse under a higher-pressure sodium lamp (white arrows indicate flowers). (C-D) Flowers of $D$. drummondii (C) and D. octopetala (D) in full bloom and in fructification. (E,F) Cuttings of $D$. drummondii at day 0 (E) and after 22 days of growth (F). Scale bars denote $1 \mathrm{~cm}$.

propagation of Dryas species was expected to be easy. For clonal propagation by cuttings, three series of ca. 20 cuttings per species were grown in a greenhouse at different times of the year. Two to three $\mathrm{cm}$ of Dryas stems containing one node were transferred into moist soil (Figure 3E) in a small growth container with a transparent plastic lid for conservation of high humidity levels. Under these conditions, $65-95 \%$ of the Dryas cuttings developed roots within 3 weeks in the absence of hormonal treatments (Figure 3F). Once the shoots had successfully rooted, the plants were transferred into single pots and grown under standard greenhouse conditions. This easy protocol for vegetative propagation of Dryas species by cuttings in the glasshouse represents an important tool for performing experiments on a high number of plants that have the same genotype, and it obviates the requirement for seeds.

\section{Hairy Root Transformation of Dryas spp.}

For a model plant, a protocol for genetic modification is important in order to analyze the expression of marker gene promoter-reporter gene fusions, or to perform reverse genetics. Hairy root transformation mediated by Agrobacterium rhizogenes is the most commonly used technique to introduce chimeric constructs into plant roots. The fact that this method does not transform the shoot is no hindrance to the study of root symbioses; A. rhizogenes-mediated hairy root transformation is routinely used not only in the model legumes Lotus corniculatus var. japonicus (Díaz et al., 2005) and Medicago truncatula (Boisson-Dernier et al., 2001) but also for actinorhizal plants like Datisca glomerata (Markmann et al., 2008), Casuarina glauca (Diouf et al., 1995) and (Imanishi et al., 2011) and non-FaFaCuRo plants like tomato (Ron et al., 2014).

In order to develop a hairy root transformation protocol, we inoculated axenically grown Dryas spp. seedlings with A. rhizogenes at different cell densities. 5 weeks after transformation, the composite plants on plate were evaluated. For D. drummondii, a transformation efficiency of $55-70 \%$ was obtained under all conditions tested, while D. octopetala plants died more frequently in response to infection with $A$. rhizogenes. The use of higher bacterial densities had a negative effect on plant survival, while lower bacterial densities reduced transformation efficiency. Here, the best compromise between low mortality and transformation rate for D. octopetala was observed when the $A$. rhizogenes suspension was adjusted to an $\mathrm{OD}_{600}$ of 1 . However, the transformation efficiency was still low with only 30\% (Figure 4A). The experiment was repeated three times using an $A$. rhizogenes suspension adjusted to an $\mathrm{OD}_{600}$ of 1 on ca. 70 seedlings per species. In all cases, the results were the same: $55-70 \%$ transformation for D. drummondii, maximally 30\% transformation for D. octopetala.

Previous studies have shown that hairy roots induced by different bacterial strains can vary in morphology and production of secondary metabolites (Thwe et al., 2016); it was also 


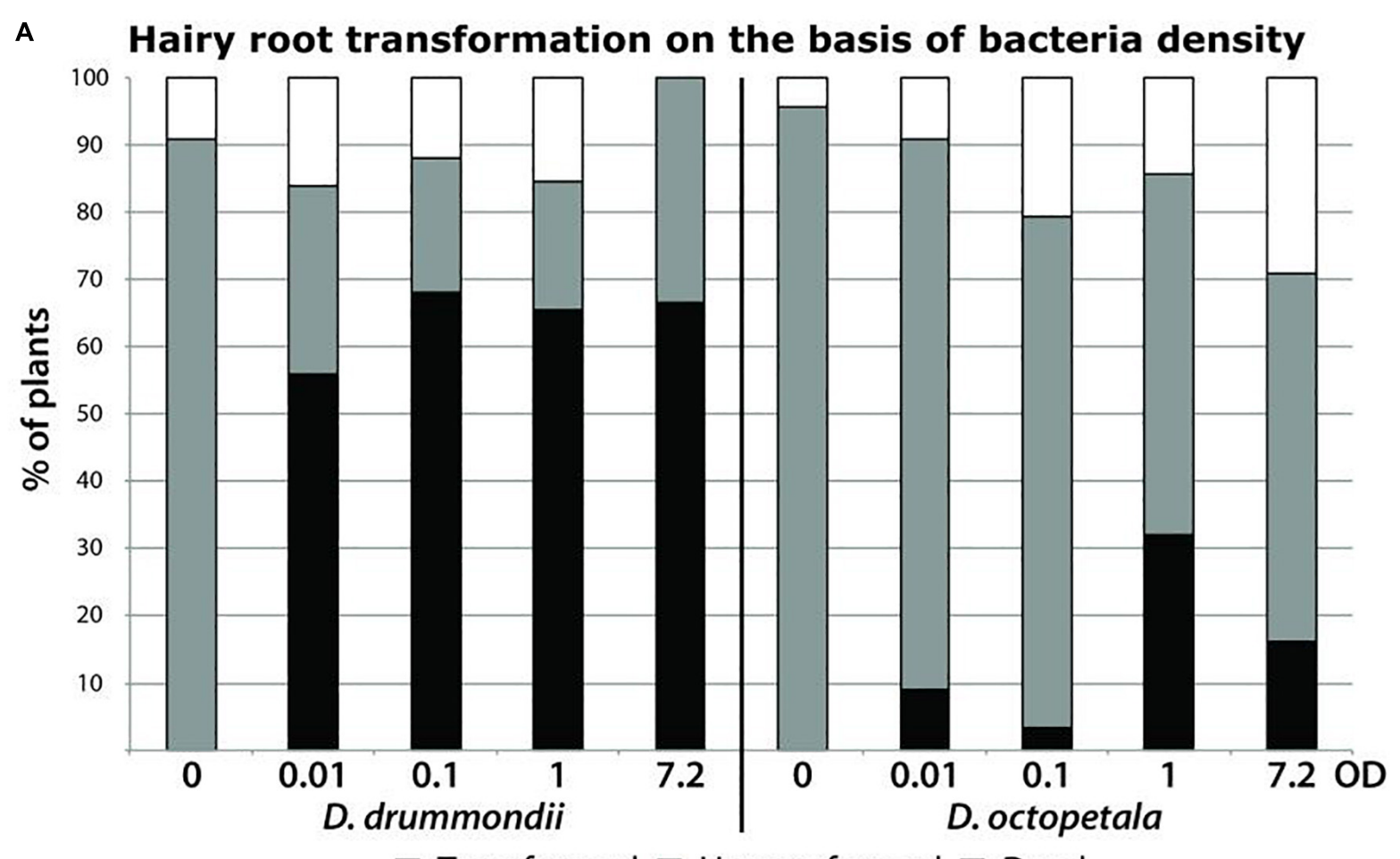

- Transformed $\square$ Untransformed $\square$ Dead

B Transformation marker visualization Sand:Vermiculite Hydroponic

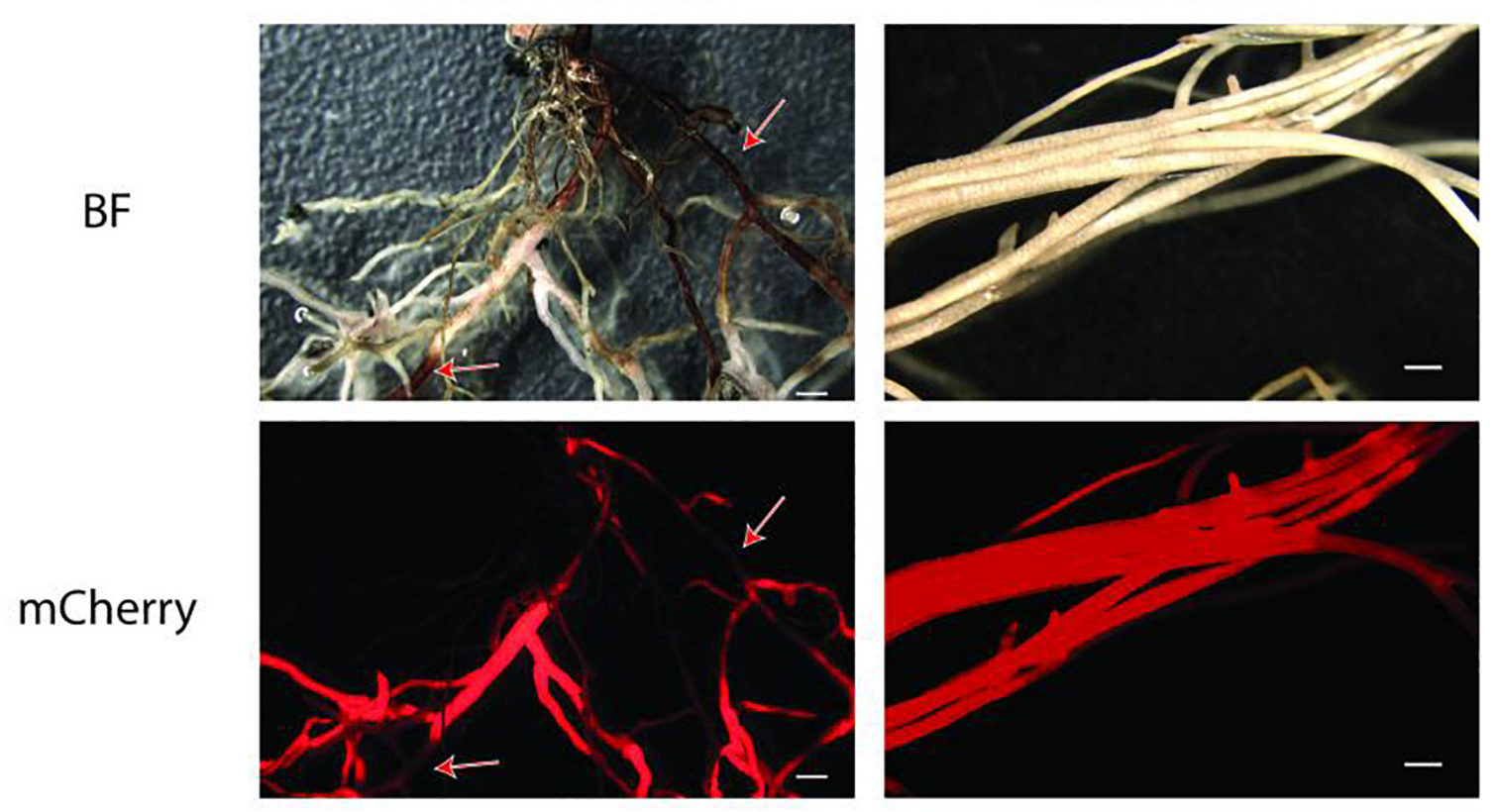

FIGURE 4 | Agrobacterium rhizogenes-mediated transformation of Dryas spp. (A) Success rates of hairy root transformation of $D$. drummondii and D. octopetala depended on the bacteria density. Percentages of dead (white boxes), surviving untransformed (gray boxes) and transformed (black boxes) root systems were determined 5 weeks after transformation on plants grown in Petri dishes. Transformation was determined based on mCherry fluorescence. (B) Visualization of the mCherry transformation marker of $D$. drummondii hairy roots after 7 weeks of growth in Weck Jars containing sand:vermiculite (left panel) vs. growth in the hydroponic system (right panel). Red arrows point at lignified part of the roots. BF = bright field; mCherry = mCherry fluorescence. Scale bars denote $1 \mathrm{~mm}$. 


\section{A}

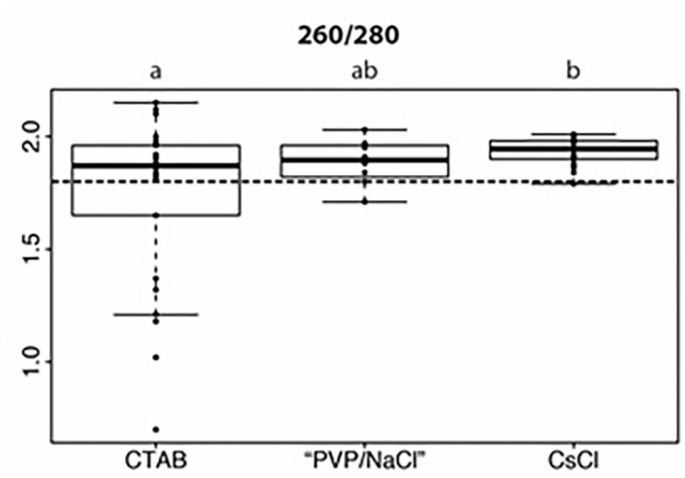

B Nucleic acid purity

260/230

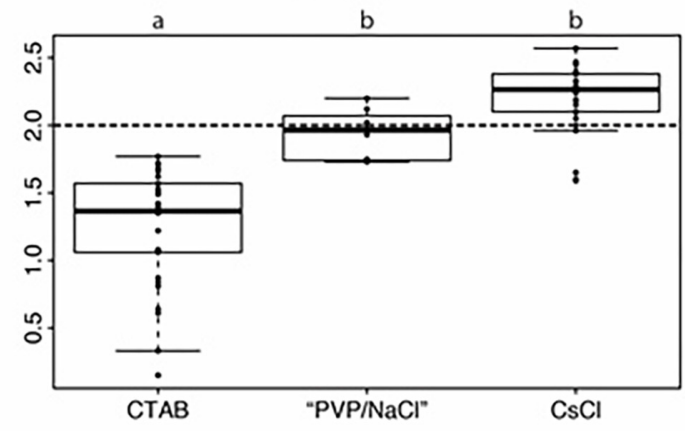

C

Agilent electropherogram summary

D. octopetala

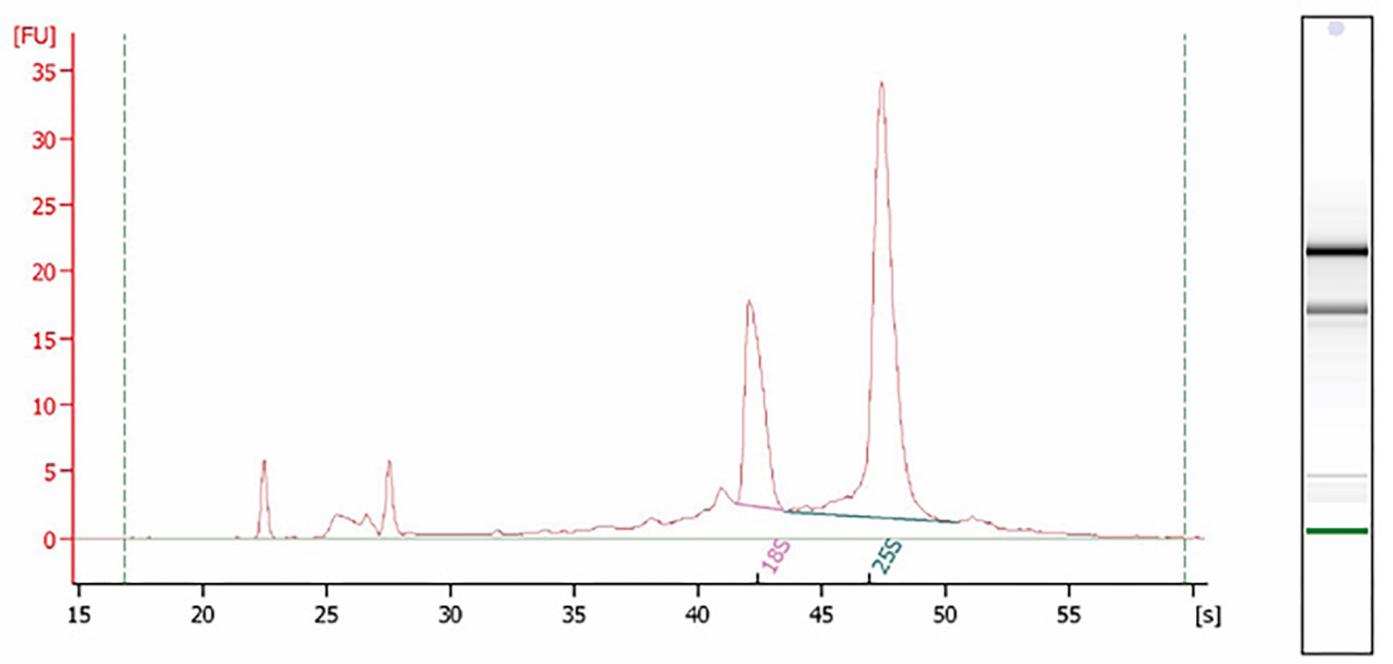

Overall Results for sample 1 :

RNA Area:

D. octopetala

RNA Concentration:

rRNA Ratio [25s/ 18s]:

194.0

RNA Integrity Number (RIN):

$8.9(8.02 .08)$

$136 \mathrm{ng} / \mu \mathrm{l}$

2.4

Result Flagging Color:

Result Flagging Label:

RIN: 8.90

Fragment table for sample 1: $\quad$ D. octopetala

$\begin{array}{lllll}\text { Name } & \text { Start Time }[s] & \text { End Time }[s] & \text { Area } & \% \text { of total Area } \\ 18 \mathrm{~S} & 41.54 & 43.44 & 30.0 & 15.5 \\ 25 \mathrm{~S} & 43.53 & 50.41 & 70.6 & 36.4\end{array}$

FIGURE 5 | Nucleic acid extractions from Dryas spp. (A,B) Ratios of UV absorbance at $260 \mathrm{~nm}$ vs. 280 or $230 \mathrm{~nm}$, from DNA samples isolated from Dryas drummondii and Dryas octopeatala using three different methods: the classical CTAB method = "CTAB"; an adapted CTAB method for difficult plants = "PVP/NaCl" and a method involving a Caesium chloride gradient centrifugation = "CsCl." An $\mathrm{OD}_{260} / \mathrm{OD}_{280}$ ratio (A) for nucleic acids vs. protein of at least 1.8 (dashed line) is generally accepted as denoting "pure DNA." $\mathrm{OD}_{260} / \mathrm{OD}_{230}$ (B) values for nucleic acids vs. polysaccharides should be higher than 2.0 (dashed line; Green and Sambrook, 2012). All DNA isolations were performed on 30 biological replicates per method. (C) Agilent Bioanalyzer electropherogram analysis of RNA isolated from D. octopetala, showing RNA integrity as determined by an RNA Integrity Number (RIN) of 8.9.

shown that plant defense reactions, phytohormone signaling and secondary metabolism could be affected by high expression levels of the agrobacterial rolB gene (Bulgakov et al., 2018). Thus, the difference in the reactions of two closely related species to the same A. rhizogenes strain is interesting. At any rate, since only one A. rhizogenes strain was used in this study, the use of other strains might leave room for further optimization of hairy root transformation of D. octopetala. 


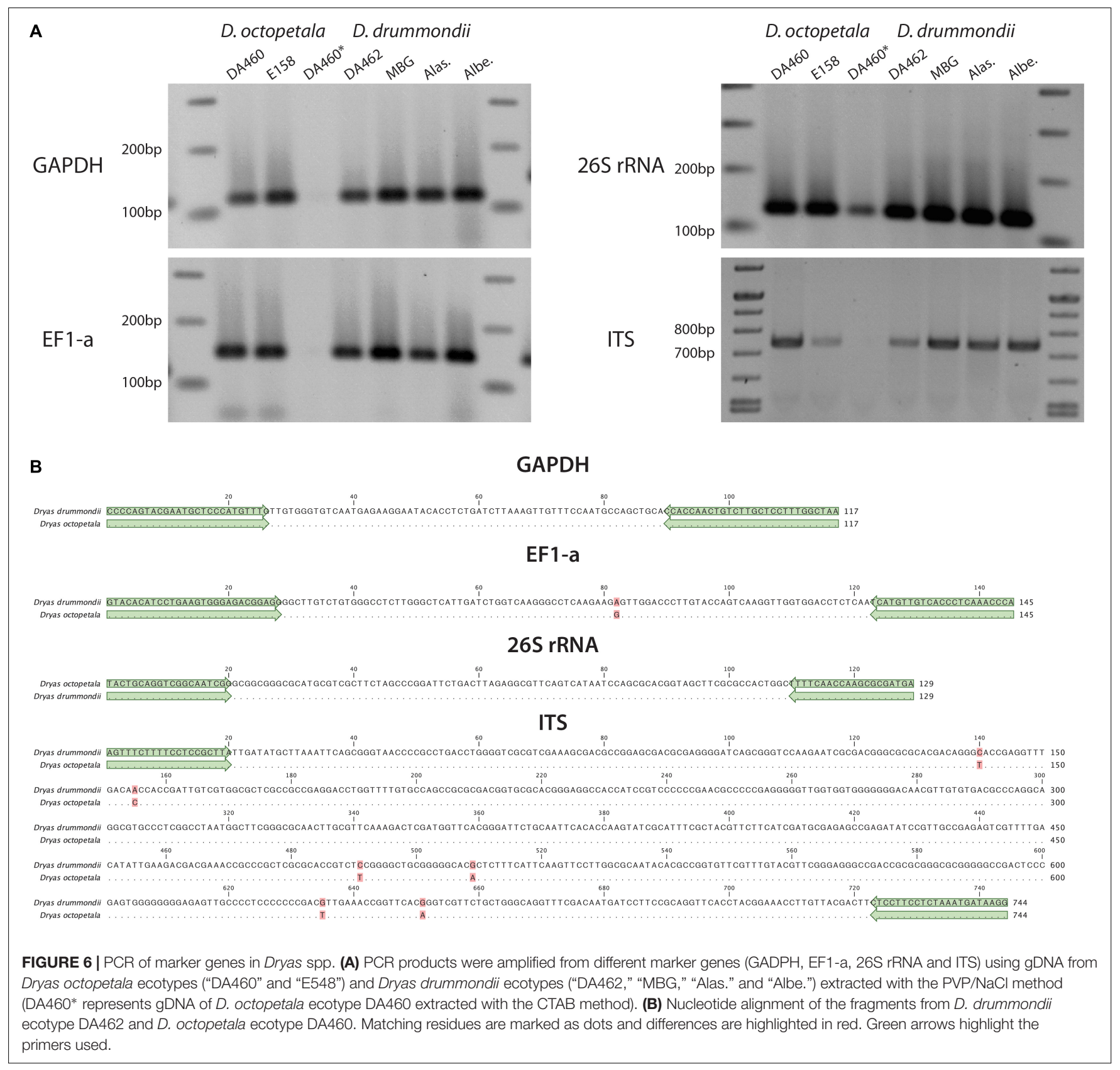

Up to 7 weeks after transfer to pots or to the hydroponic system, transgenic roots showed healthy growth and expressed the transformation marker mCherry driven by the ubiquitin promoter (Figure 4B). However, roots growing in particle substrates such as sand:vermiculite, developed sections with increased lignification, hence more autofluorescence and opacity. This led to the quenching of the mCherry signal as highlighted by the red arrows in Figure 4B. In contrast, when plants were grown in the hydroponic system, lignification was less pronounced. Thus, the hydroponic system is well suitable for the observation of fluorescent proteins in Dryas spp. hairy roots.

The ability to clone Dryas spp. genes combined with the capacity to introduce chimeric constructs into root systems opens the possibility to study Dryas genetics in depth, allowing cross-species complementation, as well as transient expression, protein localization, and reverse genetics using CRISPR/Cas or RNAi methods.

\section{Nucleic Acid Extraction From Dryas}

For molecular biological studies, DNA and RNA have to be isolated with high purity, integrity and yield to be used for sequencing or reverse transcription, respectively. This was particularly challenging since the woody nature of Dryas species and the composition of the leaves adapted to harsh environmental conditions led to the presence of contaminants interfering with nucleic acid extraction protocols. 
We tested different DNA extraction protocols on D. drummondii and D. octopetala, performing at least 30 extractions per method. DNA isolated from Dryas spp. with classical CTAB extraction protocols had an UV absorbance ratio at $260 / 280$ of $c a$. 1.8 , but the $260 / 230$ ratio was always below 1.8 , indicating polysaccharide contamination (Figures $\mathbf{5 A}, \mathbf{B}$ ). Several established DNA extraction methods were tested (Supplementary Table S1), but none of them led to a yield and purity sufficient for robust PCRs and de novo whole genome sequencing. However, a CTAB protocol adapted for recalcitrant plant material (Khanuja et al., 1999; "PVP/NaCl") by addition of PVP, followed by a high salt lysis buffer and extraction with chloroform:isoamyl alcohol (24:1, v/v), resulted in good quality DNA suitable for PCRs with reproducible results (Figure 5B). Yet, the DNA yield and quality required for genome sequencing was so far only achieved using a modified Dellaporta et al. (1983) protocol followed by a $\mathrm{CsCl}$ gradient centrifugation as described by Ribeiro et al. (1995). The DNA extracted using this last method was used for de novo whole genome sequencing performed in collaboration with the Beijing Genomics Institute (BGI, China). The first version of the $D$. drummondii genome was used in a phylogenomic comparison study by Griesmann et al. (2018).

The Spectrum ${ }^{\mathrm{TM}}$ Plant Total RNA Kit (Sigma-Aldrich) was used in order to extract RNA from different organs of Dryas spp. When Polyclar AT was added during the grinding step for recalcitrant samples (e.g., mature leaves and lignified roots), this method resulted in RNA of suitable integrity and purity for the performance of reverse transcription-quantitative PCR as indicated by the RNA integrity number (Figure 5C). RNA extracted from roots, leaves and seedlings following this method was used by the BGI in order to assist gene prediction for the D. drummondii genome (Griesmann et al., 2018). The transcripts were mapped to the protein-coding gene models, identified using the MAKER-P pipeline (version 2.31; Campbell et al., 2014), in order to obtain gene characteristics (size and number of exons/introns per gene, distribution of genes, features of splicing sites, etc.).

All method comparisons are summarized in Supplementary Table S1.

\section{PCR Amplification of Dryas spp. gDNA Fragments Using the $D$. drummondii Genome for Primer Design}

We tested the suitability of the DNA preparations resulting from different protocols as templates for PCR. Based on the published D. drummondii genome (Griesmann et al., 2018). Primers were designed based on the first version of the $D$. drummondii genome. The targets were regions in the internal transcribed spacer (ITS) of nuclear ribosomal DNA, 26S ribosomal RNA (26S rRNA), glyceraldehyde 3-phosphate dehydrogenase (GAPDH) and the

\section{REFERENCES}

Becking, J. (1970). Frankiaceae fam. nov. (Actinomycetales) with one new combination and six new species of the genus Frankia Brunchorst 1886, 174. Int. J. Syst. Evol. Microbiol. 20, 201-220. doi: 10.1099/0020771320-2-201 elongation factor 1-alpha (EF1-a). Using D. octopetala gDNA as template, fragments were amplified and sequenced as well. The amplification confirms that the DNA preparations were of sufficient quality, while high sequence conservation in these regions highlights the similarity between $D$. drummondii and D. octopetala. Indeed, the size of amplicons of both species were similar and their sequences presented few single nucleotide polymorphisms (Figure 6).

\section{Dryas as Model Genus for the Rosaceae}

With the basic but indispensable procedures and protocols for cultivation, vegetative and sexual propagation, hairy root transformation of and nucleic acid isolation from Dryas spp. described in this study, Dryas emerges as a new model genus to study important traits associated with survival in arctic and alpine conditions, including the formation of root symbioses with bacteria and ectomycorrhizal fungi.

\section{AUTHOR CONTRIBUTIONS}

KP: proposal of Dryas as a promising model system to study root symbioses. MP, BB-P, and KP: conceptualization. BB-P, AS, and KP: methodology. JF: establishment of Dryas hairy root transformation. KP and BB-P: high quality nucleic acid extraction. BB-P and AS: visualization. BB-P: writing - original draft. BB-P, AS, MP, and KP: writing - review and editing. MP: funding acquisition. MP: supervision of AS and JF. KP and MP: supervision of BB-P.

\section{FUNDING}

This project was funded by the ERC Advanced Grant "EvolvingNodules" (Project 851913-4).

\section{ACKNOWLEDGMENTS}

We thank Prof. Dr. Susanne S. Renner, director of the Nymphenburg Botanical Garden in Munich, for providing and authorizing the sampling of Dryas species in the Botanical Garden. We also thank Dr. Livia Scheunemann for providing corrections and suggestions during the writing of this manuscript.

\section{SUPPLEMENTARY MATERIAL}

The Supplementary Material for this article can be found online at: https://www.frontiersin.org/articles/10.3389/fpls.2019.00661/ full\#supplementary-material

Binder, A., Lambert, J., Morbitzer, R., Popp, C., Ott, T., Lahaye, T., et al. (2014). A modular plasmid assembly kit for multigene expression, gene silencing and silencing rescue in plants. PLoS One 9:e88218. doi: 10.1371/journal.pone. 0088218

Bjorbækmo, M. F. M., Carlsen, T., Brysting, A., Vrålstad, T., Høiland, K., Ugland, K. I., et al. (2010). High diversity of root associated fungi in both alpine 
and arctic Dryas octopetala. BMC Plant Biol. 10:244. doi: 10.1186/1471-222910-244

Bliss, L. (1958). Seed germination in arctic and alpine species. Arctic 11, 180-188. doi: 10.1002/ece3.3539

Böcher, T. W., Holmen, K., and Jakobsen, K. (1968). The Flora of Greenland. Copenhagen: P. Haase \& Son Publishers.

Boisson-Dernier, A., Chabaud, M., Garcia, F., Bécard, G., Rosenberg, C., and Barker, D. G. (2001). Agrobacterium rhizogenes-transformed roots of Medicago truncatula for the study of nitrogen-fixing and endomycorrhizal symbiotic associations. Mol. Plant Microbe Interact. 14, 695-700. doi: 10.1094/mpmi. 2001.14.6.695

Botnen, S., Vik, U., Carlsen, T., Eidesen, P. B., Davey, M. L., and Kauserud, H. (2014). Low host specificity of root-associated fungi at an Arctic site. Mol. Ecol. 23, 975-985. doi: 10.1111/mec.12646

Brunner, I., Frey, B., Hartmann, M., Zimmermann, S., Graf, F., Suz, L. M., et al. (2017). Ecology of alpine macrofungi-combining historical with recent data. Front. Microbiol. 8:2066. doi: 10.3389/fmicb.2017.02066

Bulgakov, V. P., Vereshchagina, Y. V., Bulgakov, D. V., Veremeichik, G. N., and Shkryl, Y. N. (2018). The rolB plant oncogene affects multiple signaling protein modules related to hormone signaling and plant defense. Sci. Rep. 8:2285. doi: 10.1038/s41598-018-20694-6

Campbell, M. S., Law, M., Holt, C., Stein, J. C., Moghe, G. D., Hufnagel, D. E., et al. (2014). MAKER-P: a tool kit for the rapid creation, management, and quality control of plant genome annotations. Plant Physiol. 164, 513-524. doi: 10.1104/pp.113.230144

Cheng, T., Xu, C., Lei, L., Li, C., Zhang, Y., and Zhou, S. (2016). Barcoding the kingdom plantae: new PCR primers for ITS regions of plants with improved universality and specificity. Mol. Ecol. Res. 16, 138-149. doi: 10.1111/1755-0998. 12438

Clemow, S. R., Clairmont, L., Madsen, L. H., and Guinel, F. C. (2011). Reproducible hairy root transformation and spot-inoculation methods to study root symbioses of pea. Plant Methods 7:46. doi: 10.1186/1746-4811-7-46

Cooper, W. S. (1931). A third expedition to Glacier Bay. Alaska. Ecology 12, 61-95. doi: 10.2307/1932934

Cosme, M., Fernández, I., Van der Heijden, M. G. A., and Pieterse, C. M. J. (2018). Non-mycorrhizal plants: The exceptions that prove the rule. Trends Plant Sci. 23, 577-587. doi: 10.1016/j.tplants.2018.04.004

Crawford, R. M. M. (1989). Studies in Plant Survival: Ecological Case Histories of Plant Adaptation to Adversity. Oxford: Blackwell Scientific Publications.

Crocker, R. L., and Major, J. (1955). Soil development in relation to vegetation and surface age at Glacier Bay, Alaska. J. Ecol. 43, 427-448.

Delaux, P.-M., Séjalon-Delmas, N., Bécard, G., and Ané, J.-M. (2013). Evolution of the plant-microbe symbiotic 'toolkit'. Trends Plant Sci. 18, 298-304. doi: 10.1016/j.tplants.2013.01.008

Dellaporta, S. L., Wood, J., and Hicks, J. B. (1983). A plant DNA minipreparation: version II. Plant Mol. Biol. Rep. 1, 19-21. doi: 10.1007/bf0271 2670

Díaz, C. L., Grønlund, M., Schlaman, H. R., and Spaink, H. P. (2005). "Induction of hairy roots for symbiotic gene expression studies," in Lotus japonicus Handbooks, ed. A. J. Márquez (Dordrecht: Springer), 261-277. doi: 10.1007/14020-3735-x_26

Diouf, D., Gherbi, H., Prin, Y., Franche, C., Duhoux, E., and Bogusz, D. (1995). Hairy root nodulation of Casuarina glauca: a system for the study of symbiotic gene expression in an actinorhizal tree. Mol. Plant Microbe Interact. 8, $532-537$.

Doyle, J. J., and Doyle, J. L. (1987). Genomic plant DNA preparation from fresh tissue-CTAB method. Phytochem. Bull. 19, 11-15.

Eichel, J., Corenblit, D., and Dikau, R. (2016). Conditions for feedbacks between geomorphic and vegetation dynamics on lateral moraine slopes: a biogeomorphic feedback window. Earth Surf. Process. Landf. 41, 406-419. doi: 10.1002/esp.3859

Eichel, J., Draebing, D., Klingbeil, L., Wieland, M., Eling, C., Schmidtlein, S., et al. (2017). Solifluction meets vegetation: the role of biogeomorphic feedbacks for turf-banked solifluction lobe development. Earth Surf. Process. Landf. 42, 1623-1635. doi: 10.1002/esp.4102

Fåhraeus, G. (1957). The infection of clover root hairs by nodule bacteria studied by a simple glass slide technique. J. Gen. Microbiol. 16, 374-381. doi: 10.1099/ 00221287-16-2-374
Fitter, A. H., and Parsons, W. F. J. (1987). Changes in phosphorus and nitrogen availability on recessional moraines of the Athabasca Glacier. Alberta. Can. J. Bot. 65, 210-213. doi: 10.1139/b87-028

Gamborg, O. L., Miller, R. A., and Ojima, K. (1968). Nutrient requirements of suspension cultures of soybean root cells. Exp. Cell Res. 50, 151-158. doi: 10.1016/0014-4827(68)90403-5

Geurts, R., Xiao, T. T., and Reinhold-Hurek, B. (2016). What does it take to evolve a nitrogen-fixing endosymbiosis? Trends Plant Sci. 21, 199-208. doi: 10.1016/j.tplants.2016.01.012

Gillespie, M. A. K., Baggesen, N., and Cooper, E. J. (2016). High arctic flowering phenology and plant-pollinator interactions in response to delayed snow melt and simulated warming. Environ. Res. Lett. 11:115006. doi: 10.1088/1748-9326/ $11 / 11 / 115006$

Green, M. R., and Sambrook, J. (2012). Molecular Cloning: A Laboratory Manual, 4th Edn. New York, NY: Cold Spring Harbor Laboratory Press.

Griesmann, M., Chang, Y., Liu, X., Song, Y., Haberer, G., Crook, M. B., et al. (2018). Phylogenomics reveals multiple losses of nitrogen-fixing root nodule symbiosis. Science 361:eaat1743. doi: 10.1126/science.aat1743

Hemm, M. R., Rider, S. D., Ogas, J., Murry, D. J., and Chapple, C. (2004). Light induces phenylpropanoid metabolism in Arabidopsis roots. Plant J. 38, 765-778. doi: 10.1111/j.1365-313x.2004.02089.x

Hoagland, D. R., and Arnon, D. I. (1950). The Water-Culture Method For Growing Plants Without Soil. Circular California Agricultural Experiment Station 347, 2nd edn. Berkeley: University of California.

Hultén, E. (1968). Flora of Alaska and Neighboring Territories. Stanford, CA: Stanford University Press.

Imanishi, L., Vayssières, A., Franche, C., Bogusz, D., Wall, L., and Svistoonoff, S. (2011). Transformed hairy roots of Discaria trinervis: a valuable tool for studying actinorhizal symbiosis in the context of intercellular infection. Mol. Plant Microbe Interact. 24, 1317-1324. doi: 10.1094/MPMI-03-110078

Jung, S., Ficklin, S. P., Lee, T., Cheng, C.-H., Blenda, A., Zheng, P., et al. (2013). The genome database for Rosaceae (GDR): year 10 update. Nucleic Acids Res. 42, D1237-D1244. doi: 10.1093/nar/gkt1012

Kevan, P. G. (1975). Sun-tracking solar furnaces in high arctic flowers: significance for pollination and insects. Science 189, 723-726. doi: 10.1126/science.189. 4204.723

Khanuja, S. P., Shasany, A. K., Darokar, M. P., and Kumar, S. (1999). Rapid isolation of DNA from dry and fresh samples of plants producing large amounts of secondary metabolites and essential oils. Plant Mol. Biol. Rep. $17: 74$.

Kihlman, A. O. (1890). Pflanzenbiologische Studien aus Russisch Lappland: ein Beitrag zur Kenntniss der regionalen Gliederung an der polaren Waldgrenze, Vol. 3. Helsingfors: Weilin \& Göös Buchdruckerei AG.

Kohls, S. J., Thimmapuram, J., Buschena, C. A., Paschke, M. W., and Dawson, J. O. (1994). Nodulation patterns of actinorhizal plants in the family Rosaceae. Plant Soil 162, 229-239. doi: 10.1007/bf01347710

Lambers, H., Bishop, J. G., Hopper, S. D., Laliberte, E., and Zuniga-Feest, A. (2012). Phosphorus-mobilization ecosystem engineering: the roles of cluster roots and carboxylate exudation in young P-limited ecosystems. Ann. Bot. 110, 329-348. doi: $10.1093 / \mathrm{aob} / \mathrm{mcs} 130$

Lawrence, D. B., Schoenike, R., Quispel, A., and Bond, G. (1967). The role of Dryas drummondii in vegetation development following ice recession at Glacier Bay, Alaska, with special reference to its nitrogen fixation by root nodules. J. Ecol. 55, 793-813.

Markham, J. H. (2009). Does Dryas integrifolia fix nitrogen? Botany 87, 1106-1109. doi: 10.1139/b09-071

Markmann, K., Giczey, G., and Parniske, M. (2008). Functional adaptation of a plant receptor-kinase paved the way for the evolution of intracellular root symbioses with bacteria. PLoS Biol. 6:e68. doi: 10.1371/journal.pbio.00 60068

McGraw, J. B., Turner, J. B., Chandler, J. L., and Vavrek, M. C. (2014). Disturbances as hot spots of ecotypic variation: a case study with Dryas octopetala. Arct. Antarct. Alp. Res. 46, 542-547. doi: 10.1657/1938-4246-46.3.542

Melville, L., Massicotte, H., Ackerley, C., and Peterson, R. (1988). An ultrastructural study of modifications in Dryas intergrifolia and Hebeloma cylindrosporum during ectomycorrhiza formation. Botan. Gazette 149, 408-418. doi: 10.1086/ 337733 
Murashige, T., and Skoog, F. (1962). A revised medium for rapid growth and bio assays with tobacco tissue cultures. Physiol. Plant. 15, 473-497. doi: 10.1111/j. 1399-3054.1962.tb08052.x

Newcomb, W. (1981). Fine structure of the root nodules of Dryas drummondii Richards (Rosaceae). Can. J. Bot. 59, 2500-2514. doi: 10.1139/b81-300

Nichols, G. E. (1934). The influence of exposure to winter temperatures upon seed germination in various native American plants. Ecology 15, 364-373. doi: $10.2307 / 1932351$

Normand, P., Nguyen, T. V., Battenberg, K., Berry, A. M., Vanden Heuvel, B., Fernandez, M. P., et al. (2017). Species proposal of Candidatus Frankia californiensis, the uncultured symbiont in nitrogen-fixing root nodules of a phylogenetically broad group of hosts endemic to western North America. Int. J. Syst. Evol. Microbiol. 67, 3706-3715. doi: 10.1099/ijsem.0.002147

Packer, J. G. (1994). A mountain avens, Dryas x sündermannii Kellerer ex Sündermann, in Alberta. Can. Field Natural. 108, 77-79.

Panchen, Z. A., and Gorelick, R. (2017). Prediction of Arctic plant phenological sensitivity to climate change from historical records. Ecol. Evol. 7, 1325-1338. doi: 10.1002 /ece3.2702

Parniske, M. (2018). Uptake of bacteria into living plant cells, the unifying and distinct feature of the nitrogen-fixing root nodule symbiosis. Curr. Opin. Plant Biol 44, 164-174. doi: 10.1016/j.pbi.2018.05.016

Pawlowski, K., and Bisseling, T. (1996). Rhizobial and actinorhizal symbioses: what are the shared features? Plant Cell 8:1899. doi: 10.1105/tpc.8.10.1899

Pawlowski, K., and Demchenko, K. N. (2012). The diversity of actinorhizal symbiosis. Protoplasma 249, 967-979. doi: 10.1007/s00709-012-0388-4

Perrine-Walker, F., Gherbi, H., Imanishi, L., Hocher, V., Ghodhbane-Gtari, F., Lavenus, J., et al. (2011). Symbiotic signaling in actinorhizal symbioses. Curr. Protein Pept. Sci. 12, 156-164.

Philipp, M., and Siegismund, H. R. (2003). What can morphology and isozymes tell us about the history of the Dryas integrifolia-octopetala complex? Mol. Ecol. 12, 2231-2242. doi: 10.1046/j.1365-294x.2003.01875.x

Pimprikar, P., Carbonnel, S., Paries, M., Katzer, K., Klingl, V., Bohmer, M. J., et al. (2016). A CCaMK-CYCLOPS-DELLA complex activates transcription of RAM1 to regulate arbuscule branching. Curr. Biol. 26, 987-998. doi: 10.1016/j. cub.2016.01.069

Porslid, A. E. (1947). The genus Dryas in North America. Can. Field Nat. 61, 175-192.

Potter, D., Eriksson, T., Evans, R. C., Oh, S., Smedmark, J., Morgan, D. R., et al. (2007). Phylogeny and classification of Rosaceae. Plant Syst. Evol. 266, 5-43.

Ribeiro, A., Akkermans, A., van Kammen, A., Bisseling, T., and Pawlowski, K. (1995). A nodule-specific gene encoding a subtilisin-like protease is expressed in early stages of actinorhizal nodule development. Plant Cell 7, 785-794. doi: 10.1105/tpc.7.6.785

Ron, M., Kajala, K., Pauluzzi, G., Wang, D., Reynoso, M. A., Zumstein, K., et al. (2014). Hairy root transformation using Agrobacterium rhizogenes as a tool for exploring cell type-specific gene expression and function using tomato as a model. Plant Physiol. 166, 455-569. doi: 10.1104/pp.114.239392

Roslin, T., Wirta, H., Hopkins, T., Hardwick, B., and Várkonyi, G. (2013). Indirect interactions in the High Arctic. PLoS One 8:e67367. doi: 10.1371/journal.pone. 0067367

Ryberg, M., Larsson, E., and Molau, U. (2009). Ectomycorrhizal diversity on Dryas octopetala and Salix reticulata in an alpine cliff ecosystem. Arct. Antarct. Alp. Res. 41, 506-514. doi: 10.1657/1938-4246-41.4.506

Skrede, I., Eidesen, P. B., Portela, R. P., and Brochmann, C. (2006). Refugia, differentiation and postglacial migration in arctic-alpine Eurasia, exemplified by the mountain avens (Dryas octopetala L.). Mol. Ecol. 15, 1827-1840. doi: 10.1111/j.1365-294x.2006.02908.x

Soltis, D. E., Soltis, P. S., Morgan, D. R., Swensen, S. M., Mullin, B. C., Dowd, J. M., et al. (1995). Chloroplast gene sequence data suggest a single origin of the predisposition for symbiotic nitrogen fixation in angiosperms. Proc. Natl. Acad. Sci. U.S.A. 28, 2647-2651. doi: 10.1073/pnas.92.7.2647
Stougaard, J., Abildsten, D., and Marcker, K. A. (1987). The Agrobacterium rhizogenes pRi TL-DNA segment as a gene vector system for transformation of plants. Mol. Gen. Genet. 207, 251-255. doi: $10.1007 /$ bf00331586

Thwe, A., Arasu, M. V., Li, X., Park, C. H., Kim, S. J., Al-Dhabi, N. A., et al. (2016). Effect of different Agrobacterium rhizogenes strains on hairy root induction and phenylpropanoid biosynthesis in tartary buckwheat (Fagopyrum tataricum Gaertn). Front. Microbiol. 7:318. doi: 10.3389/fmicb.2016.00318

Tiusanen, M., Hebert, P. D., Schmidt, N. M., and Roslin, T. (2016). One fly to rule them all-muscid flies are the key pollinators in the Arctic. Proc. R. Soc. B 283:20161271. doi: 10.1098/rspb.2016.1271

Tiusanen, M., Huotari, T., Hebert, P. D. N., Andersson, T., Asmus, A., Bety, J., et al. (2019). Flower-visitor communities of an arcto-alpine plant-global patterns in species richness, phylogenetic diversity and ecological functioning. Mol. Ecol. 28, 318-335. doi: $10.1111 / \mathrm{mec} .14932$

Tremblay, N., and Schoen, D. (1999). Molecular phylogeography of Dryas integrifolia: glacial refugia and postglacial recolonization. Mol. Ecol. 8, 11871198. doi: 10.1046/j.1365-294x.1999.00680.x

Vallée, G. C., Muñoz, D. S., and Sankoff, D. (2016). Economic importance, taxonomic representation and scientific priority as drivers of genome sequencing projects. BMC Genomics 17:782. doi: 10.1186/s12864-016-3100-9

Van Nguyen, T., and Pawlowski, K. (2017). "Frankia and actinorhizal plants: symbiotic nitrogen fixation," in Rhizotrophs: Plant Growth Promotion to Bioremediation, ed. S. Mehnaz (Singapore: Springer), 237-261. doi: 10.1007/ 978-981-10-4862-3_12

van Velzen, R., Holmer, R., Bu, F., Rutten, L., van Zeijl, A., Liu, W., et al. (2018). Comparative genomics of the nonlegume Parasponia reveals insights into evolution of nitrogen-fixing rhizobium symbioses. Proc. Natl. Acad. Sci. U.S.A. 115, E4700-E4709. doi: 10.1073/pnas.1721395115

Väre, H., Vestberg, M., and Eurola, S. (1992). Mycorrhiza and root-associated fungi in Spitsbergen. Mycorrhiza 1, 93-104. doi: 10.1007/bf00203256

Vitousek, P. M., Porder, S., Houlton, B. Z., and Chadwick, O. A. (2010). Terrestrial phosphorus limitation: mechanisms, implications, and nitrogen-phosphorus interactions. Ecol. Appl. 20, 5-15. doi: 10.1890/08-0127.1

Werner, G. D., Cornwell, W. K., Sprent, J. I., Kattge, J., and Kiers, E. T. (2014). A single evolutionary innovation drives the deep evolution of symbiotic $\mathrm{N}_{2}$ fixation in angiosperms. Nat. Commun. 5:4087. doi: 10.1038/ncomms5087

West, R., Andrew, R., and Pettit, M. (1993). Taphonomy of plant remains on floodplains of tundra rivers, present and pleistocene. New Phytol. 123, 203-221. doi: 10.1111/j.1469-8137.1993.tb04546.x

Wookey, P., Robinson, C., Parsons, A., Welker, J., Press, M., Callaghan, T., et al. (1995). Environmental constraints on the growth, photosynthesis and reproductive development of Dryas octopetala at a high Arctic polar semidesert. Svalbard. Oecol. 102, 478-489. doi: 10.1007/BF00341360

Xiang, Y., Huang, C.-H., Hu, Y., Wen, J., Li, S., Yi, T., et al. (2016). Evolution of Rosaceae fruit types based on nuclear phylogeny in the context of geological times and genome duplication. Mol. Biol. Evol. 34, 262-281.

Yurtsev, B. A. (1997). Analysis of evolutionary differentiation in some key arcticalpine taxa: Dryas, Oxytropis sect. Arctobia and Taraxacum sect. Arctica. Opera. Botan. 132, 27-38.

Conflict of Interest Statement: The authors declare that the research was conducted in the absence of any commercial or financial relationships that could be construed as a potential conflict of interest.

Copyright (C) 2019 Billault-Penneteau, Sandré, Folgmann, Parniske and Pawlowski. This is an open-access article distributed under the terms of the Creative Commons Attribution License (CC BY). The use, distribution or reproduction in other forums is permitted, provided the original author(s) and the copyright owner(s) are credited and that the original publication in this journal is cited, in accordance with accepted academic practice. No use, distribution or reproduction is permitted which does not comply with these terms. 